\title{
Indústria, Governança, Território: Produção Aeronáutica em São José dos Campos (SP)
}

\section{Manufacturing, Governance, Territory: Aeronautical Production in São José dos Campos (SP)}

\author{
Hoyêdo Nunes Lins* \\ Rômulo Rosa de Francisco**
}

\begin{abstract}
Resumo: O tema geral do artigo são as relações entre dinâmica industrial e dinâmica territorial. Seu foco é a indústria aeronáutica brasileira e os reflexos de suas atividades em São José dos Campos (SP), que centraliza um importante cluster aeronáutico e abriga a Empresa Brasileira de Aeronáutica S.A. (Embraer). O estudo se baseia em pesquisa bibliográfica e principalmente em entrevistas realizadas na Embraer e em empresas subcontratadas por esta, sendo a análise das interações locais guiada pelo debate sobre as relações entre economia e espaço promovido pela chamada Escola Francesa de Proximidade.
\end{abstract}

Palavras-chave: Indústria aeronáutica brasileira. São José dos Campos. Interações.

\begin{abstract}
Focusing on the relationship between industrial dynamics and territorial dynamics, the article looks at the Brazilian aeronautic industry and the effects of its operation in São José dos Campos (SP), center of an important aeronautic cluster and main location of the Empresa Brasileira de Aeronáutica S. A. (Embraer). The study is based on bibliographical research and specially on interviews undertaken both at Embraer and subcontractors, and its approach of the local interactions is guided by the discussion concerning the relationship between economy and space promoted by the so-called French School of Proximity.
\end{abstract}

Keywords: Brazilian aeronautic industry. São José dos Campos. Interactions.

JEL Classification: L62; O18.

Professor do Departamento de Ciências Econômicas e do Programa de Pós-Graduação em Economia da Universidade Federal de Santa Catarina (UFSC). E-mail: hnlins@cse.ufsc.br

** Economista pela Universidade Federal de Santa Catarina (UFSC). E-mail: s4ntor1nho@ hotmail.com 


\section{Introdução}

As últimas três décadas registraram, primeiro em países das zonas centrais da economia mundial e depois com franco espraiamento, a proliferação de estudos nos quais interesses em dinâmicas produtivas - quase sempre implicando atividades industriais - cruzam-se com interesses em dinâmicas territoriais. Inclusive no Brasil, essa articulação constitui o cerne de boa parte do que aparece como análise do desenvolvimento regional e como base da formulação de políticas de promoção. Na literatura internacional, essas abordagens mostram-se vinculadas a noções como distrito industrial, na perspectiva "italiana" (p. ex., BECATTINI, 1992) ou "britânica" (p. ex., SCHMITZ, 1995), e, mais amplamente, cluster industrial (p. ex., PORTER, 1998). Observam-se igualmente derivações que enfatizam aspectos mais ou menos específicos, como organização produtiva e custos de transação no caso da "escola californiana" (p. ex., STORPER; WALKER, 1989) e processos de aprendizagem e inovação no da "escola escandinava" (p. ex., MALMBERG; MASKELL, 1997).

Este artigo insere-se na referida tradição analítica. A dinâmica industrial aqui examinada refere-se ao setor aeronáutico, feixe de atividades com o qual poucos rivalizaram em significado de capacidade produtiva e domínio estratégico. Com efeito, na escalada industrial e tecnológica que perpassou as últimas quatro gerações, até o alvorecer do século XXI, fabricar aeronaves sempre representou indubitável coerência com o sentido de "moderno". A dinâmica econômica territorial perscrutada diz respeito a São José dos Campos, município do Vale do Paraíba, no Estado de São Paulo, que exibe um inquestionável destaque em escala nacional quanto à presença de atividades aeronáuticas. Isso é verdade quer no plano produtivo - com a presença de tecido empresarial liderado pela Empresa Brasileira de Aeronáutica S. A. (Embraer), pedra angular do setor aeronáutico no Brasil -, quer no plano institucional, em que despontam atividades de pesquisa e desenvolvimento tecnológico.

O objetivo do estudo é, após caracterizar a indústria aeronáutica de uma forma geral (seção 2) e descrever o percurso cumprido pela Embraer desde o seu surgimento (seção 3), focalizar analiticamente a problemática das interações dessa empresa com a miríade de subcontratados instalados em São José dos Campos. A abordagem escora-se não só em pesquisa bibliográfica, mas principalmente em pesquisa de campo na forma de entrevistas realizadas em outubro de 2008 por um dos autores, tanto na Embraer quanto em empresas locais que operam como prestadoras de diversos tipos de serviços à primeira. 


\section{A Indústria Aeronáutica: uma visão geral}

Pertencente a grupo de produção eletrometalmecânica que Pavitt (1984) classifica como de elevada intensidade tecnológica e inequívoca capacidade de difusão do progresso técnico, a indústria aeronáutica parte da indústria aeroespacial - exibe dois grandes segmentos produtivos no tocante à finalidade das aeronaves fabricadas: um voltado ao uso militar, o outro ao uso civil. Ambos se caracterizam por fortes exigências em termos de qualidade e pela incidência de altos custos de desenvolvimento tecnológico, mas no segmento que tem por destino o uso militar possui especial proeminência - por motivos quase óbvios - o decisivo envolvimento do Estado.

A rigor, o papel do Estado tem se revelado central no desenvolvimento de toda a indústria aeronáutica, em qualquer país. De uma parte, porque o impulso à intervenção estatal associado ao imperativo da segurança nacional e mesmo às necessidades militares em geral exibe repercussões na integralidade da trajetória setorial. De outra parte, porque entre as principais características desse segmento da indústria aeroespacial destacam-se requisitos de qualidade e desempenho impositivos de elevados gastos às empresas, assim como riscos e demora na recuperação dos investimentos efetuados: logo, nesta indústria, "[...] nem sempre os recursos necessários para seus projetos de investimento são compatíveis com a realidade do setor privado [...]" (SILVA, 2009, p. 538).

No segmento de aeronaves civis três categorias são observadas, como assinala Dagnino (1993): grande porte, com número de assentos superior a 120, médio porte ou commuters, cuja capacidade varia entre 10 e 120 assentos, e pequeno porte. As aeronaves de médio porte, com difundida utilização em transporte regional, apresentam-se segmentadas conforme a inserção nas três seguintes faixas de número de lugares: 10 a 20, 20 a 45 e mais de 45. Quanto à propulsão, esses aviões dividem-se entre os que usam motores a jato, representando a esmagadora maioria das encomendas, e os que apresentam turbo hélice. A indústria aeronáutica brasileira, ressalte-se desde logo, concentra as suas atividades na produção de aeronaves de médio porte, como se falará posteriormente a respeito da Embraer.

Deve-se ressaltar que a produção de aeronaves de porte médio exibe grande dinamismo e opera sob condições de forte concorrência. Também importante é que sua trajetória nas últimas décadas foi muito afetada pela desregulamentação do transporte aéreo estadunidense, que ocorreu no final dos anos 1970 e favoreceu a entrada no mercado de muitas empresas de menor porte, estimulando, ao mesmo tempo, o 
envolvimento de empresas maiores no transporte aéreo de amplitude regional. Nesse processo, registrou-se tendência de segmentação do mercado que se acentuou com a desregulamentação do transporte centrado nos aviões de 30 a 40 assentos.

O peso dos Estados Unidos no mercado de transporte aéreo fez aquela desregulamentação representar forte mudança nas condições de atuação dos fabricantes de aviões de porte médio. Intensificaram-se, por exemplo, as pressões por menores custos de produção e de desenvolvimento, tornando praticamente obrigatória a exploração do conceito de "família de aeronaves", que permite "economia de escopo no projeto [...] e produção. A experiência de algumas empresas tem mostrado que os custos de desenvolvimento podem ser reduzidos à metade para o segundo membro de uma família de aeronaves" (DAGNINO, 1993, p. 4). Nesse contexto, cresceu a presença entre as empresas da configuração designada "integração de sistemas", que outorga avanços em termos de compartilhamento tanto dos custos na elaboração dos projetos como dos riscos associados, abrindo caminho para certo grau de padronização de produtos e fornecedores (OLIVEIRA, 2005).

De todo modo, a produção de aeronaves de porte médio acabou implicando várias empresas de muitos países, em meio ao fortalecimento dos vínculos em torno do desenvolvimento de novas famílias. Daí que, diferentemente do que se observa na produção de aeronaves de grande porte, dominada pela europeia Airbus e pela estadunidense Boeing, a categoria de aeronaves médias ou commuters é muito menos concentrada, em termos empresariais ou geográficos. Note-se de outra parte que, como a produção aeronáutica mundial tem nos Estados Unidos um fundamental fornecedor de componentes, não surpreende que os vínculos internacionais envolvendo o desenvolvimento de novas famílias de aviões impliquem enormemente fabricantes desse país.

Mas os Estados Unidos despontam na indústria aeronáutica não só por conta do fornecimento de componentes e da influência exercida no mercado de transporte aéreo. Suas empresas - grandes corporações cujo espaço de atuação é global - dominam as correspondentes atividades. A título de ilustração, a Tabela 1 mostra que quatro das nove empresas com maiores volumes de vendas em aviação comercial no ano de 2006, representando $46 \%$ das vendas do conjunto apresentado, têm base naquele país. O único rival à altura da estadunidense Boeing é a Airbus, que representa uma divisão do consórcio europeu EADS (sigla para European Aeronautic, Defense and Space Co.), formado em 2000, e consiste na principal empresa do segmento em nível mundial. A Embraer aparece em sexto lugar nessa escala de vendas de aeronaves comerciais. 
Tabela 1 - Principais Empresas da Indústria Aeroespacial Mundial conforme o Volume de Vendas para Uso Comercial em 2006 (US\$ milhões)

\begin{tabular}{ll}
\hline Empresa & Vendas \\
\hline Airbus (divisão da EADS, um consórcio entre países & 30.610 \\
europeus & \\
Boeing (Estados Unidos) & 28.465 \\
Bombardier (Canadá) & 8.230 \\
Cessna (Estados Unidos) & 4.156 \\
Gulfstream (Estados Unidos) & 4.116 \\
Embraer (Brasil) & 3.834 \\
Raytheon/Hawker Beechcraft (Estados Unidos) & 3.100 \\
Dassault Aviation (França) & 2.579 \\
ATR (França) & 700 \\
\hline
\end{tabular}

Fonte: Warwick e Massy-Beresford (2007), com base em Pricewaterhouse Coopers.

O peso dos Estados Unidos é ainda maior na área militar (Tabela 2). Em 2006, as vendas efetuadas por suas empresas representaram $73 \%$ do movimento comercial dos nove fabricantes principais por esse critério. A Boeing, seguida por Lockheed Martin e Northrop Grumman, figura como líder, tendo o consórcio europeu EADS se mostrado em sexto lugar.

Várias dessas empresas atuam igualmente no segmento espacial, abrangendo satélites e seus lançadores e sistemas (empresas como Lockheed Martin, Boeing, EADS, Northrop Grumman, Finmeccanica). Tudo somado, nota-se hierarquia empresarial em nível planetário em cujo topo situa-se a Boeing, seguida pela EADS e depois por Lockheed Martin, situando-se a Embraer em $24^{\circ}$ lugar. Quanto a motores, despontam no alto da relação duas empresas estadunidenses - General Electric e United Technology -, representadas pelas suas correspondentes divisões. Suas vendas em 2006 corresponderam a 45\% do que negociaram as dez principais empresas em termos mundiais. A britânica Rolls-Royce e a francesa Snecma aparecem no terceiro e no quarto lugar, pela ordem.

Tabela 2 - Principais Empresas da Indústria Aeroespacial Mundial conforme o Volume de Vendas para Uso Militar (Defesa) em 2006 (US\$ milhões)

\begin{tabular}{ll}
\hline Empresa & Vendas \\
\hline Boeing (Estados Unidos) & 27.573 \\
Lockheed Martin (Estados Unidos) & 27.092 \\
\hline
\end{tabular}

(continua...) 


\begin{tabular}{|c|c|}
\hline $\begin{array}{l}\text { Northrop Grumman (Estados Uni- } \\
\text { dos) }\end{array}$ & 21.539 \\
\hline BAE Systems (Reino Unido) & 19.356 \\
\hline Raytheon (Estados Unidos) & 16.893 \\
\hline $\begin{array}{l}\text { EADS (Consórcio entre países euro- } \\
\text { peus) }\end{array}$ & 12.593 \\
\hline $\begin{array}{l}\text { United Technologies (Estados Uni- } \\
\text { dos) }\end{array}$ & 7.403 \\
\hline Finmeccanica (Itália) & 6.727 \\
\hline $\begin{array}{l}\text { L-3 Communications (Estados } \\
\text { Unidos) }\end{array}$ & 6.644 \\
\hline
\end{tabular}

A década de 2000 impôs importantes ações empresariais na indústria aeronáutica, devido às adversidades derivadas dos atentados terroristas de 11 de setembro de 2001 nos Estados Unidos e à própria exacerbação da concorrência (WARWICK; MASSY-BERESFORD, 2007). Isso não deveria surpreender, pois "a indústria do transporte aéreo não só é uma indústria centrada em torno do mercado norte-americano, como tende a permanecer nessa condição pelos próximos anos" (LIMA et al., 2005, p. 35). Houve iniciativas empresariais motivadas por esses fatores principalmente na indústria estadunidense, em que as pressões para reduzir custos e atingir novos mercados estimularam a desverticalização e a reconfiguração espacial das atividades, com estabelecimento de vínculos cooperativos abrangendo empresas de outros países (na Europa e na Ásia) e instalação de unidades no exterior até para realização de PẺD (BERNARDES, 2007). Nesse diapasão, o processo de adequação da oferta, em curso desde o final da década de 1990 e traduzida em crescente participação das aeronaves de porte médio (jatos regionais) na aviação civil dos Estados Unidos, aprofundou-se na primeira metade dos anos 2000 (LIMA et al., 2005). Isso ocorreu no bojo de um claro processo de substituição das aeronaves grandes, querendo isto dizer que o segmento produtor de aviões a jato para transporte regional não acusou - pelo menos como no outro segmento - o golpe das turbulências do início da presente década.

$\mathrm{Na}$ indústria europeia, as interações (produtivas, comerciais) são particularmente salientes devido ao peso específico do consórcio EADS e do correspondente feixe multi-empresarial e multi-institucional da Airbus, formada por BAE Systems (Reino Unido), Aérospatiale Matra 
(França), Daimler Chrysler Aerospace (Alemanha) e CASA (Espanha), com montagem final realizada em Toulouse (France) e Hamburgo (Alemanha). O alcance dessa trama de vínculos é significativo: "a trajetória da EADS resultou em solução de compromisso entre objetivos mercadológicos de maximização da eficiência econômica e objetivos políticos de harmonização de interesses público-privados, assentandose sobre o pragmatismo de sociedades territoriais que percebem a integração como estratégia para garantir soberania na conjuntura das relações internacionais" (PINTO; MIGON, 2006, p. 166). Esse arranjo europeu, cabe realçar, tem permitido à Airbus enfrentar as oscilações da demanda: "[a] vantagem competitiva da indústria de aeroestruturas europeia é derivada de uma estratégia de coordenação de uma rede regionalizada de centros de excelência de manufatura gerida pela Comissão Aeronáutica Europeia" (BERNARDES, 2007, s/p).

Especialmente importante para o assunto deste artigo é que esse caso europeu mostra-se ilustrativo sobre a importância das concentrações espaciais para o desempenho de indústrias como a aeronáutica:

Uma trajetória solidária ao processo de globalização das cadeias de fornecimento tem sido observada no movimento de aglomerações dessas indústrias em sistemas produtivos regionais de inovação. Muitas delas estão localizadas em centros de excelência, produtivos e de serviços organizados em torno de uma empresa-âncora. São exemplos o caso de Seattle (EUA), base produtiva da Boeing, e Montreal (Canadá), base da Bombardier. [...] No caso europeu, presenciamos a região de Toulouse (França, sede da Airbus), Madri e Bilbao (Espanha), onde estão localizadas empresas como a CASA e a Gamesa, ou a Sonaca na Bélgica etc. As vantagens de localização estão associadas às economias de aprendizagem e eficiência coletiva, proximidade dos centros de pesquisa e universidades, economias de especialização e possibilidade de implementação de políticas públicas regionais de desenvolvimento econômico e tecnológico efetivas (BERNARDES, 2007, não paginado).

\section{Embraer: Antecedentes, Criação e Trajetória}

O assinalado aspecto de aglomeração espacial da indústria aeronáutica faz-se presente no Brasil. Dados recentes (para 2008) sobre o emprego formal no país, disponíveis na Relação Anual de Informações Sociais (RAIS), do Ministério do Trabalho e Emprego, mostram que quase todos os postos de trabalho vinculados à fabricação de aeronaves (conforme classificação de atividades GRU CNAE 20 - Grupo 304) encontravam-se no Estado de São Paulo. Esses empregos distribuem-se 
basicamente em três municípios: São José dos Campos, Gavião Peixoto e Botucatu. Mas é São José dos Campos que possui um incontrastável destaque, pois nada menos que três quartos dos empregos em fabricação de aeronaves existentes no Brasil dizem respeito àquele município. Sobre a importância dessa atividade para tal município, basta assinalar que um terço da totalidade dos empregos da Indústria de Transformação de São José dos Campos referiam-se àquela atividade em 2008 (Tabela 3).

Tabela 3 - Empregos Formais no Setor de Fabricação de Aeronaves: Brasil, Estado de São Paulo, São José dos Campos, Gavião Peixoto e Botucatu (2008)

\begin{tabular}{l|ll|l}
\hline \multirow{2}{*}{ Unidade espacial } & \multicolumn{2}{|l|}{$\begin{array}{l}\text { Fabricação de aerona- } \\
\text { ves (GRUP CNAE 95 } \\
\text { - Grupo 304) }\end{array}$} & $\begin{array}{l}\text { Empregos da Indús- } \\
\text { tria de Transforma- } \\
\text { ção (SET IBGE) }\end{array}$ \\
\cline { 2 - 3 } & Empregos & \% & \\
\hline Brasil & 22.768 & $100[0,31]$ & $7.310 .840[100]$ \\
Estado de São Paulo & 22.206 & $97,5[0,84]$ & $2.636 .486[100]$ \\
São José dos Cam- & 17.135 & $75,3[33,88]$ & $50.578[100]$ \\
pos & & & \\
Gavião Peixoto & 2.189 & $9,6[97,37]$ & $2.248[100]$ \\
Botucatu & 2.036 & $8,9[20,17]$ & $10.092[100]$ \\
\hline
\end{tabular}

Fonte: RAIS (2008).

O que subjaz a tal concentração espacial em São José dos Campos? Basicamente a presença da Embraer, o mesmo fator, assinale-se, que permite algum destaque também para os municípios de Gavião Peixoto e Botucatu: no primeiro efetua-se a montagem de aviões para uso executivo e para defesa, e no segundo a Embraer incorporou as atividades da Indústria Aeronáutica Neiva, realizando fabricação de peças, estruturas e cablagens, além de montagem. Mas a presença marcante em São José dos Campos é, ela própria, uma derivação de movimentos anteriormente protagonizados. Recorrer à trajetória histórica é, assim, imprescindível.

O primeiro aspecto a realçar é que a Embraer, agente mais cintilante da indústria aeronáutica brasileira, há de ser considerada como reflexo da busca estratégica pelo Brasil de uma inserção no rol dos Estados com presença de atividades ligadas à fabricação de aviões. Esse aspecto - e este é o ponto que se quer realçar neste momento - é um resultado indissociável de esforços e processos protagonizados em nível de Estado brasileiro. Por exemplo, a constituição da indústria aeronáutica neste país implicou, mais de meio século atrás, o treinamento de engenheiros nacionais no exterior visando à capacitação de integrantes das forças 
armadas e, a partir disso, à absorção da tecnologia aeronáutica no plano interno. Cabe ênfase particular em iniciativas como a criação do Ministério da Aeronáutica, em 1941, acompanhado do Centro Tecnológico Aeronáutico (CTA), em 1945, e do Instituto Tecnológico de Aeronáutica (ITA), em 1950, instalado no CTA, em São José dos Campos.

É legítimo atribuir à criação do CTA, possivelmente antes de qualquer outra providência conhecida, a designação de evento decisivo na história da indústria aeronáutica brasileira. Foi no âmbito dessa instituição que surgiu e ganhou envergadura uma importante massa crítica vinculada à tecnologia aeronáutica, tendo o desempenho de tal setor no país guardado vinculação estreita com o histórico papel do CTA como centro de gravidade das atividades aeronáuticas nacionais. Esse caráter acompanha-se do sentido de foco irradiador, haja vista que essa instituição figura na origem da criação de outros organismos, vinculados a distintos níveis de ensino e pesquisa, tanto quanto exibe relevantes iniciativas em capacitação empresarial (BERNARDES, PINHO, 2002).

A Embraer constitui uma "emanação" desse processo. Criada como empresa de economia mista em 1969, com a maior parte do capital votante nas mãos do Estado brasileiro, a Embraer integra com grande realce - ostentando na verdade o maior realce - o rol de empreendimentos ligados à indústria aeronáutica nacional na forma de florescimentos a partir do CTA, empreendimentos surgidos no curso de trajetória perpassada por numerosas e férteis parcerias com a iniciativa privada. No que concerne ao seu perfil, a Embraer

[...] foi concebida como uma estatal e como uma montadora final, que se dedicaria exclusivamente à montagem de aviões através da materialização de um projeto aeronáutico endogenamente concebido. Outras companhias nacionais e estrangeiras forneceriam a maioria dos componentes [...]. Ela não buscaria verticalizar a fundo, e desnecessariamente, a produção de componentes no Brasil; mas poderia determinar com autonomia, em função da posição que ocupava e da estratégia de capacitação tecnológica que adotou, o desenvolvimento do setor. (DAGNINO, 1993, p. 11).

Cabe indicar que o projeto associado à produção do avião Bandeirantes, primeira aeronave fabricada pela Embraer e objeto de exportação ainda nos anos 1970, amalgamou diferentes interesses em torno da criação da empresa, em contexto de (correspondendo ao final dos anos 1960) estabilização econômica interna acompanhada de expansão, em meio a uma favorável conjugação de forças nos campos político e militar (FORJAZ, 2003). Além dos resultados comerciais, cujo significado transparece em participação que atingiu quase um terço 
do mercado estadunidense para aeronaves de 10 a 20 passageiros, as atividades em torno do Bandeirantes (um turbo hélice não pressurizado) possibilitaram importante aprendizagem tecnológica e estruturação das linhas de montagem e foram permeadas por vínculos de cooperação com empresas até do exterior.

Na primeira metade dos anos 1980, o agravamento das dificuldades econômicas mundiais afetou duramente os Estados Unidos e não deixou de repercutir na Embraer. Entretanto, esse quadro ensejou conduta reativa que desaguou, após a difícil experiência relativa ao pressurizado Xingu, no lançamento do Brasília, de 30 lugares. O desenvolvimento desse avião - e a subsequente família - beneficiou-se da capacidade produtiva e tecnológica acumulada (DAGNINO, 1993), merecendo realce um desempenho de vendas que significou o alcance de $29 \%$ de participação no mercado do correspondente segmento nos Estados Unidos, um resultado favorecido pela presença que a empresa já tinha logrado atingir nesse país (LEMOS et al., 2009). O percurso trilhado não prescindiu do envolvimento do setor público, pois diferentes ações governamentais se cruzaram na forma de apoio ao funcionamento da Embraer. Essas ações incluíram de benefícios fiscais e subsídios às exportações a compras governamentais, destinação de recursos para impulsionar atividades de PEBD e favorecimento na concessão de empréstimos, tudo denotando a importância estratégica atribuída pelo Estado brasileiro ao desenvolvimento da indústria aeronáutica.

A conjuntura econômica e política do final da década de 1980 e primeira metade da de 1990 mostrou-se muito adversa para a Embraer. Compunha o quadro uma preocupante queda nas vendas e na injeção de recursos públicos, sobre pano de fundo em que despontavam acenos de privatização e possível desnacionalização. Ao mesmo tempo, todavia, avançou-se no projeto do avião EMB-145, origem do ERJ-145, representando a substituição do Brasília no mercado de aeronaves de porte médio por aeronave pressurizada e a jato, além de maior. Esse avião, lançado em 1996 e correspondente a uma das duas grandes famílias de aeronaves comerciais da Embraer - com diferentes jatos de capacidade variável entre 37 e 50 assentos -, reafirmou a importância da empresa nesse segmento de mercado.

Entretanto, a evolução dos acontecimentos resultou em privatização, que ocorreu em dezembro de 1994 - antes do lançamento do novo avião - com aquisição realizada por consórcio de bancos, empresas e fundos de pensão. Iniciativa prioritária no começo da nova etapa consistiu em instalar administração profissional para recuperar empresa. De todo modo, o desenvolvimento do projeto EMB-145, que gerou o avião ERJ-145, só pode vencer as dificuldades associadas 
à crise econômica do período e aos movimentos pela privatização mediante considerável aporte de recursos pelo BNDES. Tal iniciativa frutificou, pois o lançamento da aeronave recuperou o nível de vendas da empresa: em 1996, a Embraer teve sucesso na disputa com a canadense Bombardier e conseguiu vender 200 aviões ERJ-145 nos Estados Unidos, em progressão que a tornaria "[...] empresa líder mundial de jatos regionais" (LEMOS et al., 2009, p. 31). Ressalte-se que o papel do BNDES tem sido muito importante todo o tempo desde a privatização, seja "quando os jatos regionais da Embraer ainda eram uma aposta" (PINTO; MIGON; MONTORO, 2007, p. 151), seja "[...] nos meses que se seguiram aos atentados de 11 de setembro de 2001, quando ocorreu uma grande redução na liquidez e nos financiamentos privados para companhias aéreas" (op cit., p. 151-152).

No plano da organização produtiva, as mudanças introduzidas representaram diminuição tanto dos custos de produção quanto do tempo de entrega. Mas as alterações não tiveram caráter somente tecnológico. Essenciais foram os avanços no relacionamento com os fornecedores, processo que representou a intensificação do envolvimento de parceiros de risco, quer dizer, importantes fornecedores de partes e sistemas que, concordando em receber os pagamentos só depois que a Embraer realizasse as vendas, dividiam com esta os riscos do negócio. Isso ocorreu no seio de uma efetiva reestruturação da empresa, que teve reflexos marcantes na forma como a cadeia produtiva apresentava-se organizada. Essa reestruturação percorreu o programa da aeronave ERJ-145 e apresentou consolidação durante o programa Embraer 170/190, relativo à outra das duas grandes famílias de aviões comerciais da empresa, com aeronaves cuja capacidade oscila entre 70 e 88 assentos, nos EMB-170, e entre 98 e 122 assentos, nos EMB-190. Essencial foi o consequente avanço no envolvimento de fornecedores internacionais, quer dizer, o aprofundamento do caráter internacional dos vínculos. A contraparte tomou a forma de focalização das atividades da empresa. Como assinala Quadros et al.. (2009), com efeito:

O envolvimento extensivo dos parceiros de risco com o desenvolvimento de sistemas e de módulos da estrutura do Embraer 170/190 é um ponto central na alteração da coordenação exercida na cadeia, no aumento do peso das empresas parceiras na escolha de fornecedores e na definição do investimento (e das possibilidades de nacionalização). Não menos importante, a evolução do papel desses fornecedores na cadeia de valor da Embraer - de fornecedores para parceiros de risco - criou a oportunidade para que alguns desses parceiros se transformassem também em integradores de sistemas (QUADROS et al., 2009, p. 76). 
$\mathrm{Na}$ esteira desse processo, e com estratégia voltada ao desenvolvimento de famílias de aeronaves - vantajosa e disseminada entre fabricantes de diferentes países -, a Embraer adquiriu ou pelo menos fortaleceu o perfil de "empresa integradora de uma cadeia de empresas produtoras de aeropartes, aeroestruturas e aviônicos" (LEMOS et al., 2009 , p. 26). O conjunto exibe, além dos parceiros de risco - na maioria localizados no exterior -, fornecedores que trabalham conforme as especificações (por encomenda) da contratante - também majoritariamente estrangeiros - e firmas subcontratadas que, instaladas no Brasil, especialmente na região de São José dos Campos, prestam serviços a partir das especificações repassadas e da matéria prima recebida (LIMA et al., 2005). As providências nesse sentido são consideradas estratégicas por distintos observadores. De fato,

[...] a principal inovação organizacional introduzida deu-se na relação entre a Embraer e seus fornecedores, na linha de transferência dos custos industriais para terceiros, mantendo o domínio tecnológico do produto e da sua integração (assembly) e diluindo os altos riscos decorrentes de empreendimentos com fornecedores estrangeiros, que têm acesso a capital para investimentos de baixíssimo custo em comparação com o que ocorre no Brasil. A estratégia de verticalização e de domínio das tecnologias críticas para a produção de aeronaves foi substituída pela de integração de sistemas (assembling) com tecnologia incorporada. A produção de aeronaves passou de um problema industrial tradicional (make or buy) a um problema logístico. A consequência imediata da introdução dessa nova forma de gestão foi a hierarquização da cadeia de produção em três categorias: no topo, os denominados "parceiros" [...]; em seguida vêm os "fornecedores" [...]; e, finalmente, na base da organização industrial estão os 'subcontratados', firmas que usualmente prestam serviços em atividades de menor conteúdo tecnológico, como usinagem e tratamento superficial de partes, peças e componentes, entre outras, as quais se subordinam frequentemente ao primeiro nível de "sistemistas" como insumo [...] (GOMES et al., 2005, p. 121).

De uma forma ou de outra, a trajetória da Embraer transparece nos dados de emprego da indústria aeronáutica. A figura 1, construída com base na RAIS, mostra o comportamento desses dados para o Município de São José dos Campos desde o ano da privatização até 2008, o último com informações disponíveis neste momento. Nota-se que houve declínio até 1996 e, a partir de então, crescimento ininterrupto até 2002, uma tendência que reflete o bom desempenho das vendas da Embraer. A inflexão entre 2002 e 2003 provavelmente espelha a retração derivada dos atentados de 11 de setembro de 2001 nos Estados 
Unidos, que afetaram duramente aquele mercado e, tendo em vista a representatividade deste para a Embraer, repercutiram nas operações da empresa. Mas logo depois se reingressou em percurso de expansão, algo sugestivo do dinamismo do mercado de aeronaves de porte médio ou commuters, embora o lançamento da nova família de jatos representada pelo EMBRAER 170/190, escorada em grande participação estrangeira no desenvolvimento do projeto, tenha sido importante nessa recuperação (LEMOS et al., 2009).

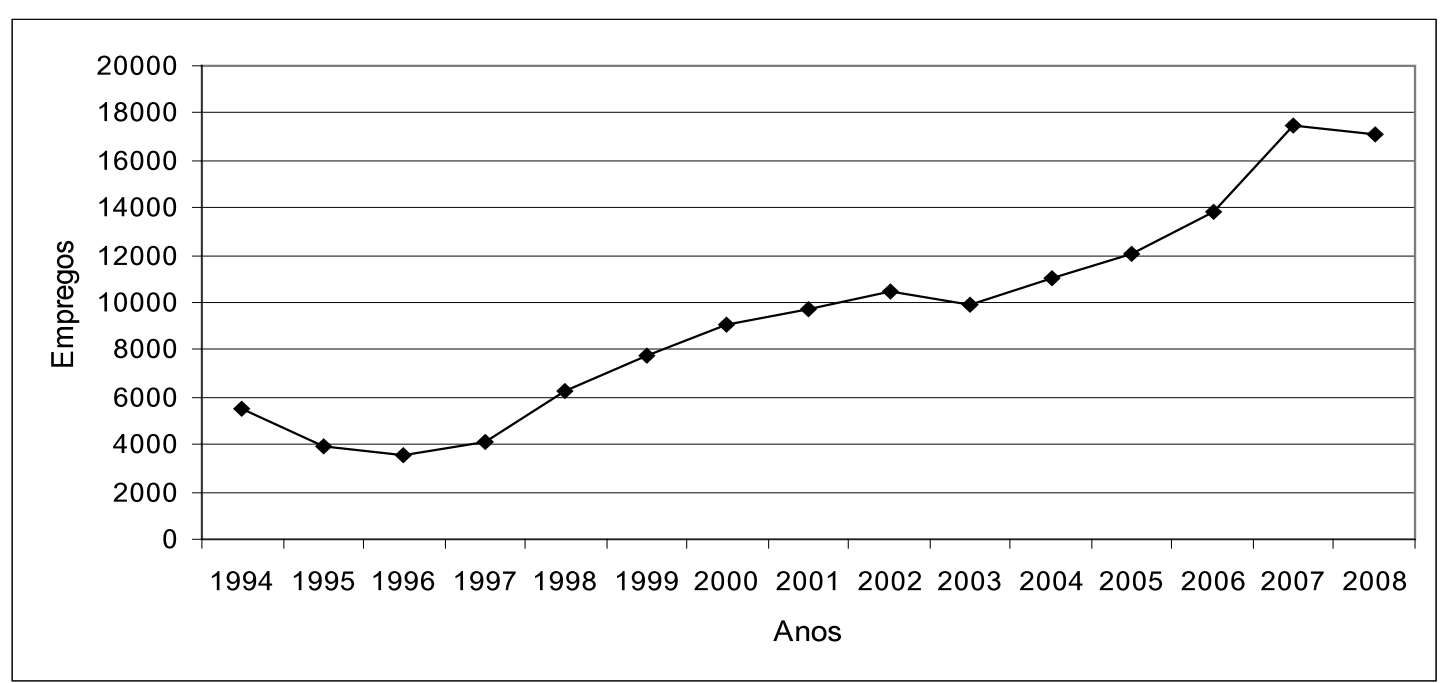

Figura 1 - Município de São José dos Campos: empregos na indústria aeronáutica - 1994-2008

Fonte: Relação Anual de Informações Sociais (RAIS).

Nota: De 1994 a 2005 os dados referem-se à classificação de atividades GRUP CNAE 96 - Grupo 353: Conwstrução, montagem e reparação de aeronaves; de 2006 em diante, por mudança na forma de apresentação dos resultados da RAIS, referem-se à classificação GRUP CNAE 20 - Grupo 304: Fabricação de aeronaves.

Até 2007, o emprego na indústria aeronáutica em São José dos Campos só fez crescer, com grandes saltos nos últimos anos da série: incremento de $15 \%$ entre 2005 e 2006 e de $26 \%$ entre 2006 e 2007. Em 2008 , contudo, a trajetória é revertida, com declínio que certamente se acentuou ao longo de 2009, a julgar por manchetes como esta, de fevereiro desse último ano: "Embraer demite 4.200 e culpa a crise" (AMATO, 2009, p. B1). A deterioração das condições de funcionamento da economia mundial, a reboque da crise vinculada ao estouro da bolha imobiliária nos Estados Unidos no segundo semestre de 2008, impôs iniciativas de reestruturação em diferentes empresas de distintos setores em vários países e regiões. A Embraer, amplamente afetada pela situação do mercado estadunidense, não foi exceção. Os cortes de emprego anunciados ocorreriam em instalações no Brasil, nos Estados 
Unidos, na França e em Cingapura. Porém, a "maioria dos desligamentos aconteceu no Brasil, sede das fábricas da empresa [...]" (ibid.).

A seção anterior foi terminada assinalando-se a importância da concentração espacial para o desempenho de atividades industriais como as que caracterizam a produção aeronáutica. Diferentes experiências internacionais estariam a sustentar esse entendimento. A presente seção foi iniciada informando que também no Brasil a indústria aeronáutica apresenta-se geograficamente concentrada, aparecendo o Estado de São Paulo e, neste, o Município de São José dos Campos como loci mediato e imediato, respectivamente, dessa concentração. Tal configuração tem na presença e no funcionamento da Embraer, ela própria uma "emanação" de processo de constituição e desenvolvimento de um setor de produção de produção aeronáutica no Brasil, a sua pedra angular. Em sintonia com tradição de estudos nos quais se cruzam interesses em dinâmicas industriais e em dinâmicas territoriais, tendo em vista a problemática do desenvolvimento local e regional, cabe indagar sobre o funcionamento do respectivo tecido produtivo territorializado.

\section{Indústria, Governança, Território: interações da Embraer em São José dos Campos}

A Embraer e seus prestadores de serviços por subcontratação localizados na área de São José dos Campos, tanto quanto instituições ao estilo do CTA e o ITA, conformam um cluster aeronáutico que, pela tipologia de espaços industriais proposta por Markusen (1995), apresenta-se como de tipo centro-radial (hub and spoke). Nessa modalidade , uma "estrutura regional se articula em torno de uma ou várias grandes corporações pertencente(s) a uma ou a algumas poucos indústrias" (Ibid., p. 15). Em termos produtivos, tal estrutura regional abriga só uma parte, todavia, do conjunto de agentes que a Embraer "integra", o qual inclui - com grande destaque devido à importância estratégica - os chamados parceiros de risco e os fornecedores que produzem sob encomenda, ambos os tipos formados por empresas majoritariamente estrangeiras. Pensar em dinâmica territorial vinculada à dinâmica produtiva significa, portanto, nesse caso, examinar principalmente as interações entre a grande empresa "integradora", articuladora e coordenadora e o tecido empresarial local.

Um útil enquadramento teórico e analítico a essa iniciativa é proporcionado pelas contribuições da chamada "Escola Francesa de Proximidade". Assim, preliminarmente ao estudo dos vínculos entre a Embraer e seus subcontratados locais, discorre-se na primeira subseção sobre alguns pontos chaves das abordagens da referida "escola". 


\subsection{Dinâmica Produtiva e Dinâmica Territorial: Termos Analíicos}

Por "Escola Francesa de Proximidade" se designa grupo de pesquisadores franceses que, desde meados dos anos 1990, em trabalhos geralmente coletivos, procuraram avançar na explicação dos efeitos da proximidade no funcionamento da economia, particularmente da economia industrial, e na endogeneização do espaço na teoria econômica. Tratou-se, historicamente, da confluência entre pelo menos dois programas de pesquisa: o de economistas industriais interessados em incorporar o espaço às suas abordagens e o de estudiosos da economia espacial interessados em investigar a dinâmica empresarial. Amplamente falando, esses autodenominados "economistas de proximidade" têm no centro de suas indagações as interfaces entre economia e espaço e a associada problemática do desenvolvimento em escala territorial (TORRE; GILLY, 2000).

Esses pesquisadores avaliam que os vínculos de proximidade são importantes para o funcionamento da economia. Na verdade, veem-nos como cruciais, seja a proximidade considerada um vetor das atividades humanas ou um resultado destas, sendo ambas as condições verdadeiras haja vista que a proximidade é simultaneamente causa e efeito dessas atividades. De fato, nessa abordagem, a noção de proximidade deriva de entendimento sobre as realidades econômica e social em que estas mostram-se relacionais.

A endogeneização do espaço na teoria econômica, perspectiva compartilhada no seio dessa "escola", implica considerar o primeiro como uma instância não neutra em termos econômicos. Falar sobre isso implica detectar o sentido atribuído ao vocábulo "território" entre esses pesquisadores. O aspecto básico a ressaltar é que se concebe o território, em sucessão de pesquisas realizadas desde os anos 1990, levando em conta as diferentes formas de proximidade percebidas e o papel da governança, sendo esta assimilada ao exercício de coordenação e às relações de poder. Com efeito, quando se referem a "território", esses pesquisadores indicam um espaço local

[...] caracterizado pelos vínculos organizacionais de firmas e [atividades de] treinamento, pesquisa e instituições que realizam outras atividades relacionadas, refletindo interesses similares e/ou complementares. Quanto mais próximos forem esses vínculos organizacionais, mais efetiva será a cooperação. Além disso, a grande proximidade é um fator poderoso no sentido de que ela coloca juntos os representantes e os interesses de membros de diferentes organizações. Portanto, o território é definido 
como: um conjunto historicamente constituído de atividades econômicas interligadas (PED, design, manufatura, comercialização) coordenado de várias maneiras por firmas, centros de pesquisa e outras agências econômicas e por governos locais e outras instituições sociopolíticas. (DUPUY; GILLY, 1999, p. 208, grifo do autor).

Entendido como constructo histórico, espelhando o que suas instituições e organizações protagonizam historicamente, o território resulta da combinação de diferentes formas de proximidade. Daí que, em vez de postulado a priori, o território é "descoberto" pela análise dessas formas (ou dimensões). Nesses termos cabe falar, em sintonia com Gilly e Perrat (2003), Gilly e Lung (2005) e Gilly e Wallet (2001), em: i) Proximidade geográfica, referindo-se a aspectos do par (antagônico) imediação-grande distância no tocante a agentes e atividades. Sua abordagem mobiliza indicações de tempo e custo, afetados pela tecnologia e a infraestrutura de transportes e comunicações, residindo aqui a percepção do que está espacialmente próximo e longe; ii) Proximidade organizacional, ligada às condições de compartilhamento de recursos pelos atores e implicando envolvimento em atividades propícias a isso numa mesma organização (como um grupo industrial) ou num tecido organizacional (um sistema produtivo local ou um setor produtivo). Esse tipo de proximidade remete às ações conjuntas para resolver problemas produtivos, baseadas na complementaridade dos recursos dos atores; iii) Proximidade institucional, recobrindo o leque de representações e pontos de referência e até o sistema de valores compartidos pelos agentes, e vinculando-se à adesão destes às regras e condutas que "canalizam" os comportamentos coletivos. Fruto de compromissos entre atores com interesses diferentes e às vezes contraditórios, essa proximidade representa alicerce da proximidade organizacional.

Esses tipos de proximidade evocam configurações produtivas cujo componente territorial é mais ou menos claro. Uma aglomeração de atividades heterogêneas e sem vínculos de complementaridade evidencia uma proximidade antes de tudo geográfica, sem as proximidades organizacional e institucional. Embora exiba economias externas, causa e efeito da própria condição de aglomerado, isso não significa presença ou influência de lógica industrial e/ou dinâmica sistêmica. Diferente é o caso de aglomeração em que há atividades complementares, fruto de processos de especialização nutridos por estrutura organizacional exibindo um setor produtivo ou até um produto como centro de gravidade. Nesse caso, a proximidade geográfica ombreia-se à organizacional, sendo claras a lógica industrial e a dinâmica sistêmica. Quando, além dos efeitos da proximidade organizacional, há maior flexibilidade em uso dos 
recursos, desenvolvimento das atividades e utilização das competências, pela coordenação entre os agentes derivada de aprendizagem coletiva, também ocorre proximidade institucional (GILLY; PERRAT, 2003).

Outro aspecto destacado pela "Escola Francesa de Proximidade" refere-se à governança. Quem fala em coordenação vinculada a processos de aprendizagem coletiva evoca antes de tudo esse tema, observando-se nos trabalhos desses pesquisadores uma concepção de governança, com as incrustadas visões de território e proximidade, que

[...] implica mecanismos produtivos e institucionais tanto na dimensão local (proximidade geográfica versus proximidade organizacional) quanto na dimensão local-global (proximidade institucional local versus proximidade institucional global). A governança territorial constitui um processo de recuperação e hibridização de proximidades institucionais. Como resultado, há uma "aliança" [...] de vários sistemas de representação. Essa 'aliança' revela e ativa o potencial produtivo das proximidades geográficas e organizacionais; o território é construído sobre a articulação das duas proximidades, levando à emergência de regularidades produtivas localizadas. Essa noção de governança territorial refere-se a processo não somente endógeno. Também envolve as relações entre instituições locais formais e informais e formas institucionais globais. (TORRE; GILLY, 2000, p. 178).

\subsection{A Embraer e seu Território}

O debate proposto pela "Escola Francesa de Proximidade" é útil para o que se pretende neste artigo porque pode representar uma espécie de "chave de leitura" sobre as relações entre grandes empresas com liderança produtiva e tecnológica e seus ambientes imediatos. Os termos daquele debate funcionam, assim, como "instrumento" para organização do olhar analítico e sua orientação para aspectos estratégicos das interações. São José dos Campos exibe irrecusavelmente, com respeito à indústria aeronáutica, proximidade geográfica na perspectiva da "Escola Francesa de Proximidade". Uma constelação de atividades enfeixadas na produção de aeronaves encontra-se instalada no município e nas proximidades (como no vizinho Município de Jacarei), realizadas pela própria Embraer - que lidera e articula, produtiva e tecnologicamente, esse tecido produtivo - e por outras empresas que interagem com a primeira. Essa dimensão da proximidade traduz-se em "imediação" que permite forte intensidade de contatos e interações face a face. Está-se falando de relações da Embraer envolvendo parceiros de risco (co-responsáveis por desenvolvimento de produto) e fornecedores, os quais, embora majoritariamente localizados no exterior, marcam pre- 
sença local e regional por meio de unidades pertencentes a companhias como a francesa Latecoère, a belga Sonaca (Sobraer S.A.) e a estadunidense CEBD Aerospace, entre outras. Faz-se referência igualmente a algumas dezenas de empresas subcontratadas, geralmente criadas por ex-funcionários da Embraer (muitos engenheiros e técnicos qualificados desligados nos piores anos da empresa em meados da década de 1990) e que prestam serviços aeronáuticos materializados em peças usinadas, estampadas e de material composto e oferecem serviços de engenharia de projetos e ferramentais, de informática e ligados a sistemas eletrônicos (LIMA et al., 2005). A proximidade geográfica inclui ainda integrantes do tecido institucional vinculado ao setor, como o CTA e o ITA.

Cabe igualmente realce à dimensão organizacional da proximidade. $O$ fato de existirem diversos agentes com atuação especializada, evocando uma clara e espacialmente inscrita divisão do trabalho, sugere a ocorrência de importantes complementaridades. Isso indica a existência de condições para compartilhamento de recursos e iniciativas conjuntas objetivando a resolução de problemas produtivos com base na complementaridade das ações desses agentes e seus atributos. Note-se que recursos podem ser compartilhados no âmbito de estruturas produtivas e institucionais distribuídas espacialmente, como no interior de um grupo industrial presente em várias localizações distantes entre si, querendo isso dizer que a proximidade organizacional não exige, necessariamente, proximidade geográfica. A Embraer pode ser considerada nesses termos, pois exibe estrutura com plantas produtivas em diferentes localizações no Brasil - além de São José dos Campos, possui em Gavião Peixoto e Botucatu - e no exterior - joint ventures na China e em Portugal - e unidades não produtivas ainda mais disseminadas internacionalmente (Estados Unidos, França, Cingapura e China). O foco aqui, todavia, é o cluster aeronáutico, e sobre isso parece não haver equívoco na afirmação de que, ao lado das economias externas (decorrentes da própria condição de aglomerado e simultaneamente esteios dessa condição), São José dos Campos ostenta "lógica industrial" e dinâmica sistêmica. Em síntese pode-se falar, para essa aglomeração, em proximidade geográfica acompanhada de proximidade organizacional.

Quanto à dimensão institucional da proximidade, pode-se considerála presente por conta da conjugação dos interesses dos vários agentes no desempenho do setor aeronáutico, com possível convergência, em algum grau, de condutas e ações coerentes com isto. A trajetória do aglomerado aeronáutico significou processo de aprendizagem coletiva amparado, entre outros aspectos, na proliferação de empresas de menor porte criadas por ex-funcionários da Embraer que passaram a atuar como subcontratados na prestação de diferentes tipos de produtos e 
serviços, seja em manufatura, seja em projetos e desenvolvimento. Como assinalou o engenheiro chefe do setor de projetos especiais da Embraer entrevistado por um dos autores, a empresa contrata fora tudo o que considera mais apropriado obter junto a outros agentes, o que significa reconhecimento de competência no tecido empresarial local integrante da sua rede de fornecimento. Destacou-se na entrevista que a Embraer inclusive protagoniza numerosos projetos de desenvolvimento de atividades em cooperação com outras empresas locais e com instituições públicas (como o já mencionado ITA). Ora, é difícil imaginar iniciativas dessa natureza sem a presença de comportamentos coletivos "canalizados" e de compromissos estabelecidos entre os agentes, no marco de uma coordenação efetiva em que sobressai o papel da Embraer, numa palavra, sem proximidade de tipo institucional.

Desse cruzamento de proximidades, particularmente a geográfica e a organizacional, é possível derivar que, devido à trajetória da indústria aeronáutica em São José dos Campos e refletindo o que tem sido realizado, historicamente e de maneira conjugada, por suas diferentes empresas e instituições, a região em foco constitui um território no sentido utilizado pela "Escola Francesa de Proximidade". De sua parte, a governança protagonizada envolve mecanismos, dizendo respeito tanto à produção quanto aos sistemas de representação e regulação de condutas coletivas - quer dizer, à proximidade institucional -, que operam na dimensão local e nas dimensões local e global simultaneamente.

Esse entendimento sobre a governança encontra amparo na própria estrutura da cadeia produtiva da Embraer. Como sublinhado, tal cadeia é composta, além de empresas locais que interagem com a primeira mediante vínculos de subcontratação envolvendo atividades de menor conteúdo tecnológico, também por parceiros de risco (que figuram no topo da estrutura) e por fornecedores (em posição intermediária) localizados principalmente no exterior. Essa estrutura deriva, ressalte-se, de opção da Embraer pela focalização em certas competências principais, uma estratégia que, se "possibilitou a sobrevivência e o crescimento da empresa, [...] acarretou a redução nos índices de nacionalização, transferindo muitas vezes para o exterior decisões e [...] atividades que antes eram realizadas no país" (PINTO; MIGON; MONTORO, 2007, p. 158). Daí poder-se falar, para essa situação e em sintonia com a abordagem da "Escola de Proximidade", em "aliança" de distintos sistemas de representação, ou seja, em "hibridização" de proximidades institucionais incidentes em nível local e em nível global. Isso se justifica tanto mais porque parceiros de risco viraram integradores de subsistemas da Embraer, mudando o prevalecente formato da governança. 
Entre os programas ERJ 145 e Embraer 170/190, a cadeia de valor da indústria aeronáutica brasileira evoluiu dinamicamente de um arranjo em que predominava a hierarquia e a modularização como formas de coordenação para uma estrutura mais distribuída e predominante relacional, ainda que se tenham hierarquizado mais os níveis de fornecedores. Os vínculos mais significativos da cadeia, do ponto de vista dos valores comercial e tecnológico, são os que se estabelecem entre a Embraer e seus parceiros de risco e são governados de maneira relacional. Eles correspondem aos principais elementos da arquitetura da aeronave: propulsão; sistemas aviônicos, de ar condicionado, hidráulico e pneumático; estrutura, sistema de trem de pouso; e interiores. Os parceiros de risco responsáveis por subsistemas, por sua vez, estabelecem interações predominantemente modulares com seus fornecedores de componentes Os parceiros de risco responsáveis por estruturas e interiores instituem interações mais tipicamente relacionais com seus fornecedores de equipamentos e mais tipicamente de mercado com fornecedores de matérias primas (QUADROS et al., 2009, p. 84-85).

Mas o que se pode dizer sobre esse entrecruzamento de proximidades, que autoriza falar em "território", pelo ângulo das possibilidades para as empresas de menor porte que operam como subcontratadas pela Embraer? Qual o significado das interações com a empresa líder para o tecido empresarial que figura na base da organização industrial do setor aeronáutico, no que concerne à dinâmica inovativa e ao robustecimento da capacidade competitiva? Esse tipo de questão é fundamental sobretudo quando a problemática do desenvolvimento local ou regional associada à dinâmica industrial constitui foco de atenção.

Para formar uma ideia sobre o assunto entrevistaram-se cinco dessas empresas, todas localizadas em São José dos Campos e com atividades iniciadas, na maioria dos casos, em meados da década de 1990. São empresas que prestam diferentes serviços para a Embraer e têm parte substancial do seu faturamento dependente desse vínculo: só uma declarou situação em que menos da metade das vendas se relacionava com tais atividades. Com a exceção de uma empresa, o ano de início do funcionamento coincide com o do começo da prestação de serviços para a Embraer, sugerindo a influência representada pela existência desta na própria decisão de criar aquelas empresas (Quadro 1). Estas não aparecem identificadas no corpo do texto, mas se encontram nomeadas no anexo, ao final. 


\begin{tabular}{|l|l|l|l|l|}
\hline Empresas & $\begin{array}{l}\text { Início das } \\
\text { atividades }\end{array}$ & $\begin{array}{l}\text { Atividades realizadas } \\
\text { para a Embraer }\end{array}$ & $\begin{array}{l}\text { Início da } \\
\text { ativid. p/ } \\
\text { Embraer }\end{array}$ & $\begin{array}{l}\text { \% das vendas } \\
\mathbf{p} / \text { Embraer }\end{array}$ \\
\hline A & 1998 & $\begin{array}{l}\text { Estamparia, usinagem, } \\
\text { montagens aeronáuticas }\end{array}$ & 1998 & 50 \\
\hline B & 1995 & $\begin{array}{l}\text { Prestação de serviços } \\
\text { terceirizados de fabr. de } \\
\text { aviões }\end{array}$ & 1995 & 25 \\
\hline C & 1997 & $\begin{array}{l}\text { Desenho mecânico, } \\
\text { computação gráfica, } \\
\text { plotagens }\end{array}$ & 2002 & 80 \\
\hline D & 1995 & $\begin{array}{l}\text { Fabricação de peças e } \\
\text { estruturas aeron. em } \\
\text { composites }\end{array}$ & 1995 & 80 \\
\hline E & 2003 & $\begin{array}{l}\text { Tapeçaria industrial, isola- } \\
\text { mento acústico }\end{array}$ & 2003 & 90 \\
\hline
\end{tabular}

Quadro 1 - Caracterização geral das empresas locais entrevistadas que atuam como subcontratadas pela Embraer

Fonte: Elaborado pelo autor a partir de pesquisa de campo realizada em outubro de 2008.

Essas empresas se dividem entre um subgrupo, minoritário, que tem a Embraer como cliente exclusivo no setor aeronáutico e um outro que atua para outras empresas desse setor e de outros setores, como o automobilístico. De todo modo, todas declararam que apenas seguem parâmetros determinados pela Embraer, obedecendo as especificações repassadas, ou só efetuam atividades parciais em projetos desta (Quadro 2). Esses vínculos, como assinalado em entrevista pelo entrevistado engenheiro chefe do setor de projetos especiais da Embraer, são majoritariamente regidos por contratos que duram o tempo da prestação do serviço, e não por contratos de médio ou longo prazo. A situação desse painel de empresas é ilustrativa, portanto, de algumas impressões mais amplas captadas por outros estudos, mais abrangentes.

[Trata-se geralmente de] empresas [...] que recebem a matéria prima e o desenho da Embraer, vendendo à empresa serviços por homem-hora ou por máquina-hora. Ela fornece os insumos (alumínio aeronáutico, material composto etc.) e moldes, especificação e desenhos para as empresas subcontratadas, que, por sua vez, prestam serviços [...] cujas etapas finais de tratamento de superfície e montagem de subsistemas são realizadas posteriormente pela própria Embraer (LIMA et al., 2005, p. 46-47).

Mesmo assim, pelo que se vê no Quadro 2, a grande maioria das empresas entrevistadas considerou que as interações com a Embraer outorgaram aprendizagem, com variedade de aspectos e de alcance. 
O fato de diversos proprietários terem sido funcionários da Embraer, e/ou de integrantes dos contingentes assalariados apresentarem essa condição, foi apontado pelos entrevistados como um importante fator de aprendizagem. Todas assinalaram, com efeito, transferência de know-how por meio de suas interações com a empresa líder. Porém, é preciso cautela na avaliação dessas informações, pelo que sugerem outros estudos mais abrangentes.

Embora esse movimento da cadeia aeronáutica estimule trajetórias de aprendizado importantes, [...] essa expansão vem ocorrendo mediante a apropriação de baixa intensidade tecnológica para ampla maioria das empresas locais, basicamente processos de aprendizagem limitados à ampliação da base produtiva e capacitação operacional [...] e muito pouco associados à capacidade inovativa [...]. (BERNARDES; OLIVEIRA, 2002, p. 104).

\begin{tabular}{|c|c|c|c|c|c|}
\hline Empresas & $\begin{array}{l}\text { Embraer é } \\
\text { única cliente } \\
\text { no setor }\end{array}$ & $\begin{array}{l}\text { Status da } \\
\text { atividade p/ } \\
\text { a Embraer }\end{array}$ & $\begin{array}{l}\text { Aprendizagem } \\
\text { do vínculo c/ } \\
\text { Embraer }\end{array}$ & $\begin{array}{l}\text { Mecanismos de } \\
\text { aprendizagem }\end{array}$ & $\begin{array}{l}\text { Transferência } \\
\text { de know-how }\end{array}$ \\
\hline $\mathbf{A}$ & $\begin{array}{l}\text { Não; tem } \\
\text { outros clientes } \\
\text { no setor e na } \\
\text { indústria auto- } \\
\text { mobilística }\end{array}$ & $\begin{array}{l}\text { Apenas } \\
\text { segue } \\
\text { parâmetros, } \\
\text { obedecendo } \\
\text { especifica- } \\
\text { ções } \\
\end{array}$ & $\begin{array}{l}\text { Sim, conhecimen- } \\
\text { to dos processos }\end{array}$ & $\begin{array}{l}\text { Obtenção na } \\
\text { Embraer; dono } \\
\text { é ex-funcionário }\end{array}$ & $\begin{array}{l}\text { Sim; } \\
\text { usinagem e } \\
\text { montagem }\end{array}$ \\
\hline B & $\begin{array}{l}\text { Não; tem } \\
\text { outros clientes } \\
\text { no setor e } \\
\text { na indústria } \\
\text { em geral, } \\
\text { em pintura e } \\
\text { modelagem }\end{array}$ & $\begin{array}{l}\text { Apenas } \\
\text { segue } \\
\text { parâmetros, } \\
\text { obedecendo } \\
\text { especifica- } \\
\text { ções }\end{array}$ & $\begin{array}{l}\text { Sim, capacitação } \\
\text { de mão de obra }\end{array}$ & $\begin{array}{l}\text { Obtenção via le- } \\
\text { arning by doing; } \\
\text { ex-funcionários } \\
\text { no quadro }\end{array}$ & $\begin{array}{l}\text { Sim; layout } \\
\text { e design de } \\
\text { fábrica e } \\
\text { gestão }\end{array}$ \\
\hline C & $\begin{array}{l}\text { Sim; além } \\
\text { da Embraer } \\
\text { atende setores } \\
\text { de telecomu- } \\
\text { nicações e } \\
\text { eletrônica }\end{array}$ & $\begin{array}{l}\text { Só executa } \\
\text { projetos } \\
\text { solicitados; } \\
\text { exclusivos da } \\
\text { Embraer }\end{array}$ & $\begin{array}{l}\text { Não, conheci- } \\
\text { mento em dese- } \\
\text { nho expandido de } \\
\text { componentes }\end{array}$ & $\begin{array}{l}\text { Obtenção na } \\
\text { Embraer; dono } \\
\text { é ex-funcionário }\end{array}$ & $\begin{array}{l}\text { Sim; design } \\
\text { de peças e } \\
\text { componentes } \\
\text { em grande } \\
\text { escala }\end{array}$ \\
\hline D & $\begin{array}{l}\text { Não; tem ou- } \\
\text { tros clientes no } \\
\text { setor e nas ind. } \\
\text { mecân. e de } \\
\text { instrumentos } \\
\text { médicos }\end{array}$ & $\begin{array}{l}\text { Só testa inte- } \\
\text { gridade dos } \\
\text { compon.; } \\
\text { projetos são } \\
\text { da Embraer }\end{array}$ & $\begin{array}{l}\text { Sim, tecnologia } \\
\text { de composites } \\
\text { e requisitos de } \\
\text { qualidade }\end{array}$ & $\begin{array}{l}\text { Obtenção na } \\
\text { Embraer; donos } \\
\text { são ex-funcio- } \\
\text { nários }\end{array}$ & $\begin{array}{l}\text { Sim; produ- } \\
\text { ção e gestão } \\
\text { de materiais } \\
\text { compostos }\end{array}$ \\
\hline $\mathbf{E}$ & $\begin{array}{l}\text { Sim; além da } \\
\text { Embraer só } \\
\text { atende indús- } \\
\text { tria automobi- } \\
\text { lística }\end{array}$ & $\begin{array}{l}\text { Apenas } \\
\text { segue } \\
\text { parâmetros, } \\
\text { obedecendo } \\
\text { especifica- } \\
\text { ções }\end{array}$ & $\begin{array}{l}\text { Sim, incorporação } \\
\text { de novos mate- } \\
\text { riais e processos }\end{array}$ & $\begin{array}{l}\text { Obtenção via } \\
\text { controle de } \\
\text { qualidade e de } \\
\text { processos }\end{array}$ & $\begin{array}{l}\text { Sim; design e } \\
\text { conceito de } \\
\text { produtos e } \\
\text { normas técn. }\end{array}$ \\
\hline
\end{tabular}

Quadro 2 - Significado dos vínculos com a Embraer para as empresas entrevistadas Fonte: Elaborado pelo autor a partir de pesquisa de campo realizada em outubro de 2008. 
Realmente, em que pese as indicações sobre aprendizagem e transferência de know-how, o quadro geral de capacitação das empresas que prestam serviços à Embraer permite pouco entusiasmo. O engenheiro chefe do setor de projetos especiais da segunda indicou frustrações em investidas para contratar certos serviços ou produtos junto a empresas locais. O principal motivo tem sido a precariedade, comparando ao que é demandado pela Embraer, do parque fabril relativamente à engenharia do prestador de serviço, à capacidade tecnológica ou à certificação. Isso é ilustrativo dos principais problemas da base local da organização industrial do setor aeronáutico, ressaltados em estudos como o de Lemos et al. (2009): ao lado da restrita escala de produção e da fragilidade financeira dessas empresas, atribui-se importância às carência na capacitação tecnológica em engenharia aeronáutica, eletrônica e materiais compostos, entre outras. Vale sublinhar que tal quadro reflete trajetória de inserção normalmente baixa e episódica de empresas brasileiras de menor porte entre os fornecedores da Embraer. Nesse percurso, as adversidades dos anos 1990 se revelaram dramáticas para essas empresas, que foram sendo "relegadas ao plano de subcontratadas, especializando-se em atividades de menor conteúdo tecnológico e, portanto, sujeitando-se a um menor poder de barganha e de acesso ao crédito" (GOMES et al., 2005, p. 122). Pouco favorável, tal situação permaneceu após a privatização, já que "a Embraer continuou com seu tradicional descolamento da cadeia produtiva nacional, que se encontra marginalizada do processo de expansão da empresa" (Ibid., p. 29).

O quadro 3 informa a percepção das empresas entrevistadas sobre o significado das suas interações com a Embraer para a dinâmica inovativa, a obtenção de informações tecnológicas e o desenvolvimento de PEDD. Observa-se diversificação das principais fontes tecnológicas, variando de instituições locais (como o CTA) às feiras e aos contatos com clientes, incluindo a própria Embraer e os fornecedores, e divisão das empresas quanto à presença ou não de PEBD. Mas o quadro geral no tocante a PEBD parece precário, sendo sugerido um limitado alcance das atividades implicadas. Sobre as consequências das interações com a Embraer para geração de inovação em produto ou processo, todos os entrevistados responderam positivamente. Todavia, na quase totalidade dos casos foram assinalados reflexos restritos à qualificação da força de trabalho e à capacidade operacional, no sentido do aumento, em termos gerais. No tocante à capacidade inovativa propriamente dia, praticamente nada foi indicado. É provável que entre as razões dessa situação figure o que é destacado por Bernardes e Oliveira (2002). 
A análise das relações produtivas e tecnológicas estabelecidas entre a EMBRAER e suas fornecedoras locais revela a debilidade de um padrão de eficiência e aprendizado coletivo [...], pois as relações interfirmas são bastante centralizadas, verticalizadas, hierarquizadas, não ultrapassando os processos de treinamento para o atendimento aos requisitos técnicos, não havendo quase nenhuma cooperação horizontal. (BERNARDES; OLIVEIRA, 2002, p. 115).

\begin{tabular}{|l|l|l|l|}
\hline Empresas & $\begin{array}{l}\text { Vínculo c/ Embraer gerou } \\
\text { inovação em processo ou } \\
\text { produto }\end{array}$ & $\begin{array}{l}\text { Fontes tecnológicas } \\
\text { principais }\end{array}$ & Presença de PछD \\
\hline A & $\begin{array}{l}\text { Sim; implicou capacitar e } \\
\text { treinar funcionários }\end{array}$ & $\begin{array}{l}\text { Várias instituições } \\
\text { locais, incluindo o CTA }\end{array}$ & $\begin{array}{l}\text { Sim, em processo, com 8 } \\
\text { funcionários }\end{array}$ \\
\hline B & $\begin{array}{l}\text { Sim; implicou qualificar mão } \\
\text { de obra p/ fabricação }\end{array}$ & $\begin{array}{l}\text { Contatos com clientes } \\
\text { e feiras }\end{array}$ & Não, mas pretende \\
\hline C & $\begin{array}{l}\text { Sim; implicou novos sof- } \\
\text { twares e máquinas e mais } \\
\text { funcionários e espaço físico }\end{array}$ & Sem fontes específicas & Não \\
\hline D & $\begin{array}{l}\text { Sim; implicou processos e } \\
\text { produtos especiais }\end{array}$ & $\begin{array}{l}\text { Embraer e fornece- } \\
\text { dores }\end{array}$ & $\begin{array}{l}\text { Sim, em qualidade da pro- } \\
\text { dução, c/ 3 funcionários }\end{array}$ \\
\hline E & $\begin{array}{l}\text { Sim; implicou aumentar } \\
\text { escala e eficiência }\end{array}$ & $\begin{array}{l}\text { Como processos são } \\
\text { manuais, capacitação } \\
\text { da mão de obra é } \\
\text { crucial }\end{array}$ & $\begin{array}{l}\text { Sim, sem especificidades, } \\
\text { e só com o proprietário }\end{array}$ \\
\hline
\end{tabular}

Quadro 3 - Interações das empresas entrevistadas com a Embraer e reflexos em inovação, fontes tecnológicas e presença de PEBD

Fonte: Elaborado pelo autor a partir de pesquisa de campo realizada em outubro de 2008.

Chama a atenção, de outra parte, que todas as empresas tenham atribuído importância à sua localização no cluster aeronáutico de São José dos Campos. Aspectos de proximidade geográfica e proximidade organizacional permeiam as respostas, que trazem referências às externalidades: mão de obra capacitada, presença de clientes e inserção em tecido setorialmente especializado e caracterizado por "cultura local" própria da indústria aeronáutica - a "atmosfera industrial" aludida por Marshall (1979) - são fatores registrados. Ao mesmo tempo, entretanto, três das cinco empresas entrevistadas indicaram que suas relações no âmbito do cluster são fracas, quando não praticamente inexistentes. É ilustrativo que a Embraer tenha sido mencionada tanto como empresa com a qual a interação é forte, em meio a relações gerais precárias, quanto como empresa com a qual se fazia necessário "melhorar o vínculo" (Quadro 4). 


\begin{tabular}{|c|c|c|}
\hline Empresas & $\begin{array}{l}\text { Atributos/razões da } \\
\text { localização }\end{array}$ & $\begin{array}{l}\text { Apreciação das relações de que } \\
\text { participa na aglomeração }\end{array}$ \\
\hline $\mathbf{A}$ & $\begin{array}{l}\text { Representa proxim. c/ clien- } \\
\text { tes, acesso a mão de obra } \\
\text { capacitada e inserção em } \\
\text { ambiente c/ grande conheci- } \\
\text { mento aeronáutico enraizado }\end{array}$ & $\begin{array}{l}\text { Boas relações, incluindo cooperação com } \\
\text { concorrentes, com razoável integração }\end{array}$ \\
\hline B & $\begin{array}{l}\text { Representa envolvimento } \\
\text { com cultura local voltada ao } \\
\text { setor aeronáutico e proximi- } \\
\text { dade com clientes }\end{array}$ & $\begin{array}{l}\text { Relações fracas, de baixa interatividade com } \\
\text { outros agentes, embora almeje mudar a } \\
\text { situação }\end{array}$ \\
\hline C & $\begin{array}{l}\text { Concentração geográfica } \\
\text { de muitas atividades ligadas } \\
\text { ao setor aeronáutico; dono } \\
\text { mora há mais de } 30 \text { anos na } \\
\text { cidade }\end{array}$ & $\begin{array}{l}\text { Relações positivas, embora seja neces-sário } \\
\text { melhorar vínculo com Embraer }\end{array}$ \\
\hline $\mathbf{D}$ & $\begin{array}{l}\text { Representa proximidade com } \\
\text { clientes }\end{array}$ & Nenhuma relação, praticamente \\
\hline $\mathbf{E}$ & $\begin{array}{l}\text { Representa proxim. c/ clientes } \\
\text { e acesso a mão de obra } \\
\text { qualificada; família mora na } \\
\text { cidade }\end{array}$ & $\begin{array}{l}\text { Relações fracas, sendo a Embraer o único } \\
\text { agente com o qual há intensa interação }\end{array}$ \\
\hline
\end{tabular}

Quadro 4 - Importância atribuída pelas empresas entrevistas à sua localização e às interações locais das quais participa

Fonte: Elaborado pelo autor a partir de pesquisa de campo realizada em outubro de 2008.

De todo modo, foi possível notar na pesquisa de campo que a Embraer aplica cláusulas em seus contratos de fornecimento que empresas subcontratadas chamaram de "leoninas". Para alguns entrevistados, isso não seria sem consequências na base da estrutura industrial do setor aeronáutico instalada na região de São José dos Campos. A rigor, contudo, a percepção entre essas empresas é heterogênea, refletindo o que estaria a caracterizar a própria conduta da empresa líder com a sua rede de subcontratados locais. Como assinalado por Quadros et al. (2009),

[...] a Embraer, hoje, apresenta um comportamento dual quanto aos seus fornecedores nacionais de bens, ferramental e processos industriais: se, por um lado, ela procura abandonar a configuração de cadeia cativa, adotando um discurso de incentivo à autonomia e à independência, mesmo dos pequenos fornecedores, por outro, a configuração de dependência de uma cadeia cativa é ainda observada. [...] Assim, é possível registrar queixas de fornecedores quanto ao tratamento recebido [...], ao grau de 
exigências, à falta de contrato de fornecimento e às poucas contrapartidas oferecidas, como também constatar a existência de outros que estão satisfeitos com a relação com a empresa, que enaltecem visitas técnicas constantes e o apoio que recebem nas atividades produtivas. (QUADROS et al., 2009, p. 170).

\section{Considerações Finais}

A produção aeronáutica, praticamente sinônima de indústria moderna, não é estranha ao Brasil, que não só fabrica como exporta aeronaves, destacando-se mundialmente no segmento de aviões de porte médio. Esse desempenho é pilotado pela Embraer, emanação de um processo amparado em decisivo envolvimento do Estado e pontuado pela criação e operação de instituições cujo papel foi essencial. Como em países de forte presença na cena aeronáutica mundial, também no Brasil as atividades correspondentes apresentam-se concentradas espacialmente. Salientou-se no texto que São José dos Campos é centro de gravidade de uma região que aglutina o essencial das atividades aeronáuticas efetuadas no Brasil, embora a cadeia produtiva da Embraer abarque de modo significativo agentes - parceiros de risco e grandes fornecedores - localizados em outros países. Na área de São José dos Campos, operam principalmente subcontratados de pequeno e médio porte que constituem a base local da produção aeronáutica realizada no país.

Pensar em dinâmica territorial associada à dinâmica industrial, no que concerne à indústria aeronáutica no Brasil, implica, assim, em grande medida, refletir sobre as interações entre a Embraer e essa base local. Nos termos do debate proposto pela Escola Francesa de Proximidade, pode-se assinalar a convergência das proximidades geográfica, organizacional e institucional no aglomerado aeronáutico centrado em São José dos Campos, representando um território no sentido privilegiado no corpo do artigo.

Porém, com base tanto em pesquisa de campo como em outros estudos, indicou-se que a situação dos integrantes dessa base local merece um olhar crítico, falando em termos gerais. Essas empresas tendem a prestar serviços à Embraer, não só por meio de contratos temporários mas também envolvendo atividades que implicam tão somente a obediência de parâmetros definidos e impostos pela empresa líder, numa típica operação de venda de serviços específicos. De uma maneira ampla, isso representa, para esses subcontratados, apropriação de baixa intensidade tecnológica e processos de aprendizagem que não transcendem significativamente a ampliação da base produtiva e da 
capacidade operacional (capacitação da mão de obra, por exemplo), sem de fato repercutir no plano da capacidade de inovação. Daí vir essa base produtiva territorialmente incrustada apresentando limitações nas esferas da engenharia e da capacitação tecnológica, algo assinalado até em entrevista realizada na própria Embraer por um dos autores deste artigo. Outro aspecto detectado na pesquisa de campo e observado também em outros estudos é que essas empresas locais apresentam-se fortemente dependentes das encomendas da Embraer, um problema que se soma ao de uma condição financeira via de regra débil e que lhes reduz a capacidade de negociação e barganha.

Fortalecer o envolvimento das empresas de menor porte que formam a base local da indústria aeronáutica na cadeia produtiva tornouse assim, nos anos 2000, um importante objetivo de política industrial, particularmente abraçado no âmbito do BNDES. Pela capacitação produtiva e tecnológica desse tecido empresarial, vislumbrava-se igualmente aumentar o conteúdo nacional dos produtos da cadeia. Após um primeiro passo que consistiu em identificar os problemas enfrentados pelas empresas, procurou-se detectar oportunidades de atuação competitiva no âmbito da produção de partes, peças e componentes e sistemas, objetivando-se igualmente a promoção de exportações para fabricantes de aeronaves localizados em outros países. Observe-se que, por ter a Embraer aprofundado a estratégia de parcerias de risco, transferindo para grandes fornecedores - alguns dos quais com capacidade produtiva instalada na região de São José dos Campos - importantes decisões sobre produção e organização industrial, as possibilidades das empresas de menor porte locais e o próprio aumento do índice de nacionalização passou a depender cada vez mais do comportamento desses grandes parceiros (PINTO; MIGON; MONTORO, 2007).

Houve avanços na operação de empresas da base local, principalmente devido à maior profissionalização administrativa e à intensificação da concentração mediante fusões e aquisições. $\mathrm{O}$ anúncio, em maio de 2007, da decisão de unificar as operações da Winnstal (especializada particularmente em estamparia e integrante do painel de empresas entrevistadas na pesquisa de campo) e da Friuli (com presença na área de usinados), daí resultando a WF Structures $\mathcal{E}$ Systems, constitui uma ilustração mais ou menos recente desse processo (NAKAMURA, 2007).

Resultados interessantes foram observados notadamente por conta de iniciativas como o consórcio de pequenas e médias empresas de capital nacional intitulado High Technology Aeronautics (HTA), criado em 2002 na área de São José dos Campos, majoritariamente por ex-funcionários da Embraer (uma das empresas entrevistadas na pesquisa de campo, a Alltec, é integrante). Essas empresas, hoje em número de sete (cf. www. 
hta.com.br) e com "competência em engenharia e projetos, usinagem $\mathrm{CNC}$ e convencional, materiais compostos, montagem de componentes e chapas e execução de testes e ensaios não destrutivos" (GOMES et al, 2005, p. 130), foram acompanhadas na iniciativa pela Agência Brasileira de Promoção de Exportações e Investimentos (APEX) - pois a exportação era um objetivo buscado - e pelo CTA. Gomes et al.. (2005) assinalam que, ao lado de vantagens como competitividade dos preços praticados, qualificação da mão de obra e proximidade com a Embraer, o HTA padece de dificuldades no plano financeiro, insuficiência de escala e uma certa desatualização tecnológica. Seja como for, Lemos et al.. (2009) avaliam que esse consórcio é um dos melhores "[...] exemplos de produtores capacitados a participar ativamente na rede de fornecedores da Embraer ou mesmo se tornar independente dela exportando parte significativa da produção [...]" (LEMOS et al., 2009, p. 34).

Todavia, os desdobramentos da crise financeira desencadeada pelo estouro da bolha imobiliária nos Estados Unidos no último trimestre de 2008 têm se revelado dramáticos para a base industrial local da indústria aeronáutica. O motivo é o conjunto de ajustes realizados pela Embraer em face da deterioração nas condições de mercado, que se traduziram em drástico corte nas encomendas no tecido empresarial da região. Agravado pela situação de endividamento de muitas empresas junto a fabricantes de bens de capital, esse quadro repercutiu na cadeia produtiva em reduções na jornada de trabalho, em desativação (ao menos temporária) de atividades e, nos casos mais drásticos, em demissões, ditas inevitáveis em várias empresas devido aos prejuízos acumulados (SILVEIRA, 2009).

Não admira, portanto, que o BNDES tenha aprovado, em novembro de 2009, duas novas modalidades de aporte de recursos no seio do Programa BNDES de Financiamento às Empresas da Cadeia Produtiva Aeronáutica Brasileira (BNDES Pró-Aeronáutica). Um deles é o BNDES Pró-Aeronáutica Exportação, que mira uma maior participação de empresas de menor porte dessa cadeia no mercado internacional. $O$ outro é o BNDES Pró-Aeronáutica Empresa, o qual, focado nos fornecedores de menor porte, volta-se para o desenvolvimento de produtos e serviços aeronáuticos no esquema de parceria de risco: a aprovação de contrato de risco entre o cliente e o fornecedor é requisito para a aprovação do financiamento (BNDES, 2009).

Do ponto de vista do desenvolvimento local e regional, a crise das pequenas e médias empresas da cadeia aeronáutica no momento atual estaria a mostrar os limites das políticas de promoção em indústrias globalizadas, como se trata no caso em questão. A dinâmica produtiva e a capacidade competitiva da base territorial dessa indústria são determinadas em escala ampla, global, um traço acentuado pelas próprias 
opções da Embraer em termos de organização dos seus vínculos em nível de cadeia. Os parceiros de risco e os grandes fornecedores são, como frisado, grandes empresas internacionais que simultaneamente reagem àqueles determinantes globais e contribuem para o seu perfil e intensidade. Assim pode-se dizer que, em situações como a produção aeronáutica em São José dos Campos, a dinâmica industrial - perpassada por forças estruturais que operam em escala planetária - impõe-se amplamente à dinâmica territorial, evocando-se aqui o foco de interesse da Escola Francesa de Proximidade, que se propõe a contribuir para a análise das relações entre ambas dinâmicas. Conceber e implementar políticas de desenvolvimento em realidades socioterritoriais assim caracterizadas constitui, sem dúvida, um grande e instigante desafio. De todo modo, o tema da cooperação entre empresas e envolvendo instituições há de figurar com destaque em quaisquer tentativas nessa direção.

\section{Referências}

AMATO, F. Embraer demite 4.200 e culpa a crise. Folha de São Paulo, p. B6, 20 fev. 2009.

BECATTINI, G. Le district industriel: milieu créatif. Espace et Sociétés, n. 66-67, p. 147163, 1992.

BERNARDES, R. Competitividade da indústria aeronáutica: uma comparação internacional. Revista Eletrônica de Jornalismo Científico, n. 84, fev. 2007. Disponível em: <www. comciencia.br/comciencia >. Acesso em 1 out. 2009.

BERNARDES, R.; OLIVEIRA, A. Novos territórios produtivos, mudança tecnológica e mercado de trabalho: o caso de São José dos Campos. Dados: Revista de Ciências Sociais, v. 45, n. 1, p. 99-137, 2002.

BERNARDES, R.; PINHO, M. Aglomeração e aprendizado na rede de fornecedores locais da Embraer. Rio de Janeiro: UFRJ, Rede de Sistemas Produtivos e Inovativos Locais, set. 2002.

BNDES amplia programa Pró-Aeronáutica e inclui exportação e pequenas empresas. 2009. Disponível em: < http://www.bndes.gov.br/SiteBNDES/bndes/bndes_pt/Institucional/Sala_de_Imprensa/Noticias/2009/Industria/20091126_aeronautica.html>. Acesso em: 10 dez. 2009.

DAGNINO, R. Competitividade da indústria aeronáutica. Estudo da Competitividade da Indústria Brasileira. Nota Técnica Setorial do Complexo Metal-Mecânico, Campinas: IE/ UNICAMP-IEI/UFRJ-FDC-FUNCEX, 1993.

DUPUY, C.; GILLY, J-P. Industrial groups and territories: the case of Matra-Marconi-Space in Toulouse. Cambridge Journal of Economics, v. 23, n. 2, p. 207-223, 1999.

FORJAZ, M. C. S. As origens da Embraer: o projeto estratégico da Aeronáutica. São Paulo, Relatório de Pesquisa n. 22, Núcleo de Pesquisas e Publicações da Fundação Getúlio Vargas/EAESP, 2003.

GOMES, S. B. V. G. et al.. O desafio do apoio ao capital nacional na cadeia de produção de aviões no Brasil. Revista do BNDES, v. 12, n. 23, p. 119-134, jun. 2005. 
GILLY, J-P.; LUNG, Y. Proximités, secteurs et territories. Cahiers du GRES, Bordeaux: IFReDE; Toulouse: LEREPS, n. 9, 2005.

GILLY, J-P.; PERRAT, J. La dynamique institutionnelle des territories: entre gouvernance locale et régulation globale. Cahiers du GRES, Bordeaux: IFReDE; Toulouse: LEREPS, n. 5, 2003.

GILLY, J.-P.; WALLET, F. Forms of proximity, local governance and the dynamics of local economic spaces: the case of industrial conversion processes. International Journal of Urban and Regional Research, v. 25, n. 3, p. 553-570, 2001.

LEMOS, M. B. et al.. Indústria aeronáutica. Agência Brasileira de Desenvolvimento Industrial. Projeto "Estudo sobre como as empresas brasileiras nos diferentes setores industriais acumula conhecimento para realizar inovação tecnológica". Belo Horizonte, fev. 2009.

LIMA, J. C. C. O. L. et al.. A cadeia aeronáutica brasileira e o desafio da inovação. BNDES Setorial, n. 21, p. 31-55, mar. 2005.

MALMBERG, A.; MASKELL, P. Towards an explanation of regional specialization and industry agglomeration. European Planning Studies, v. 5, n. 1, p. 25-41, 1997.

MARKUSEN, A. Áreas de atração de investimentos em um espaço econômico cambiante: uma tipologia de distritos industriais. Nova Economia, v. 5, n. 2, p. 9-44, 1995.

MARSHALL, A. Principles of economics: an introductory volume. 8. ed. London: Macmillan, 1979.

NAKAMURA, P. Fornecedores da Embraer unem forças. Valor Econômico, p. B6, v. 16, maio 2007.

OLIVEIRA, L. G. A cadeia de produção aeronáutica no Brasil: uma análise sobre os fornecedores da Embraer. 2005. Tese (Doutorado em Política Científica e Tecnológica) - Universidade Estadual de Campinas, Campinas, 2005.

PAVITT, K. Sectoral patterns of technical change: towards a taxonomy and a theory. Research Policy, v. 13, n. 6, p. 343-373, 1984.

PINTO, M. A. C.; MIGON, M. N. Alternativas para o adensamento da cadeia produtiva aeronáutica brasileira: o "modelo europeu”. BNDES Setorial, n. 24, p. 139-179, set. 2006.

PINTO, M. A. C.; MIGON, M. N.; MONTORO, G. C. F. Convergência público-privada no adensamento da cadeia produtiva aeronáutica brasileira. Revista do BNDES, v. 14, n. 28, p. 145-170, dez. 2007.

QUADROS, R. et al.. Mapeamento da cadeia produtiva aeronáutica brasileira (CAB). In: MONTORO, G. C. F.; MIGON, M. N. (Org.). Cadeia produtiva aeronáutica brasileira: oportunidades e desafios. Rio de Janeiro: BNDES, p. 71-196, 2009.

PORTER, M. E. Clusters and the new economics of competition. Harvard Business Review, v. 76, n. 6, p. 77-90, 1998.

SCHMITZ, H. Collective efficiency: growth path for small-scale industries. The Journal of Development Studies, v. 31, n. 4, p. 529-566, 1995.

SILVA, C. G. R. S. Políticas internacionais de promoção da indústria aeronáutica. In: MONTORO, G. C. F.; MIGON, M. N. (Org.). Cadeia produtiva aeronáutica brasileira: oportunidades e desafios. Rio de Janeiro: BNDES, p. 483-539, 2009.

SILVEIRA, V. Crise sufoca fornecedor da Embraer. Valor Econômico, 12 ago. 2009. 
STORPER, M.; WALKER, R. The capitalist imperative: territory, technology, and industrial growth. New York: Basil Blackwell, 1989.

TORRE, A.; GILLY, J.-P. On the analytical dimension of proximity dynamics. Regional Studies, v. 34, n. 2, p. 169-180, 2000.

WARWICK, G; MASSY-BERESFORD, H. Capacity crunch. Flight International, p. 30-47, sep. 2007.

\section{Anexo: relação dos subcontratados} da Embraer entrevistados na pesquisa de campo

Winnstall - Winner Instalações Industriais

SERCO - Serco Cooperativa de Serviços e Engenharia

Bacci - Bacci Desenhos e Reproduções Sc Ltda.

Alltec - Alltec Indústria de Componentes em Materiais Compostos Ltda.

Paulo Tap - Tapeçaria do Paulinho

Recebido: 12/02/2010.

Aceito: 25/11/2010. 